\title{
Electrocardiographic and morphometric features in patients with ventricular tachycardia of right ventricular origin
}

\author{
J Kazmierczak, J De Sutter, R Tavernier, C Cuvelier, C Dimmer, L Jordaens
}

\begin{abstract}
Objective-To study differences between repetitive monomorphic ventricular tachycardia (RMVT) of right ventricular origin, and ventricular tachycardia in arrhythmogenic right ventricular dysplasia (ARVD).

Patients-Consecutive groups with RMVT $(n=15)$ or ARVD $(n=12)$, comparable for age and function.

Methods-Analysis of baseline, tachycardia, and signal averaged ECGs, clinical data, and right endomyocardial biopsies. Pathological findings were related to regional depolarisation (QRS width) and repolarisation (QT interval, QT dispersion).
\end{abstract}

Results-There was no difference in age, ejection fraction, QRS width in leads I, V1, and V6, and QT indices. During ventricular tachycardia, more patients with ARVD had a QS wave in V1 $(p<0.05)$. There were significant differences for unfiltered QRS, filtered QRS, low amplitude signal duration, and the root mean square voltage content. In the absence of bundle branch block, differences became nonsignificant for unfiltered and filtered QRS duration. Mean (SD) percentage of biopsy surface differed between RMVT and ARVD: normal myocytes (74(3.4)\% $v$ $64.5(9.3) \%$; p < 0.05); fibrosis $(3(1.7) \% v$ $8.9(5.2) \%$; $p<0.05)$. When all patients were included, there were significant correlations between fibrosis and age $(r=0.6761)$, and fibrosis and QRS width $(r=0.5524$ for lead $I ; r=0.5254$ for lead $\mathrm{V} 1$; and $r=0.6017$ for lead V6).

Conclusions-The ECG during tachycardia and signal averaging are helpful in discriminating between ARVD and RMVT patients. There are differences in the proportions of normal myocytes and fibrosis. The QRS duration is correlated with the amount of fibrous tissue in patients with ventricular tachycardia of right ventricular origin.

(Heart 1998;79:388-393)

Keywords: arrhythmogenic right ventricular dysplasia; electrocardiography; endomyocardial biopsy; ventricular arrhythmias

Pathology, University Hospital of Ghent C Cuvelier

Correspondence to: Prof Dr Jordaens.

Accepted for publication 11 December 1997
It is not always easy to differentiate idiopathic or repetitive monomorphic ventricular tachycardia (RMVT) of right ventricular origin from tachycardia in early stages of arrhythmogenic right ventricular dysplasia (ARVD). ${ }^{1}$ From a clinical point of view, the major points helpful in the recognition of RMVT remain the absence of overt cardiomyopathy and myocardial dysfunction. ${ }^{2}$ A good tolerance of the arrhythmia (which does not exclude symptoms) is also suggestive of RMVT. ${ }^{3}$ RMVT is thought to have a good long term prognosis. Unfortunately, patients affected by ARVD in the early stages often also have a normal heart at routine examination and even after full noninvasive and invasive investigations the diagnosis is not always definite. This is embarrassing, as some patients with ARVD may experience palpitations due to minor ventricular arrhythmias, while others may die suddenly. ${ }^{4}$ Furthermore, ARVD can progress to left ventricular disease, making confusion with other pathology possible (for example, dilated cardiomyopathy). ${ }^{5}$

To improve our understanding of the two diseases, we analysed clinical data, routine ECG data, ECG data during ventricular tachycardia, QT measurements, and signal averaged electrocardiograms (ECGs) in two groups of consecutive patients with RMVT and ARVD. Right ventricular biopsies were not only subjected to routine analysis but morphometric analysis was also performed and the results were correlated with the electrocardiographic data.

\section{Methods}

PATIENTS

The study population included 27 consecutive patients, as described in table 1 , with ventricular tachycardia of right ventricular origin as defined by ECG criteria, and without coronary artery disease. Patients with overt cardiomyopathy with dilatation of the left ventricle or depressed left ventricular ejection fraction or both were excluded. The patients were divided into two different groups: 12 patients had ARVD and 15 (idiopathic) RMVT. A prospective diagnosis of ARVD was made using criteria published by the task force of the working group on myocardial and pericardial disease of the ESC. ${ }^{6}$ In the ARVD group, $42 \%$ had a family history of ARVD or sudden cardiac death. Six patients (50\%) had echocardiographic or angiographic evidence of global or regional dysfunction of the right ventricle. $T$ wave inversion in the right precordial leads was present in six patients $(50 \%)$. Clinical ventricular tachycardia with left bundle branch block (LBBB) morphology was present in 11 patients, and in one at electrophysiological study, 
Table 1 Demographic data for the study groups

\begin{tabular}{llll}
\hline Variable & RMVT $(n=15)$ & ARVD $(n=12)$ & $p$ value \\
\hline Mean age (years) (SD) & $35(11)$ & $38(13)$ & $\mathrm{NS}$ \\
Male/female (n) & $10 / 5$ & $10 / 2$ & $\mathrm{NS}$ \\
Mean EF (\%) (SD) & $61(8)$ & $66(16)$ & $\mathrm{NS}$ \\
BBB (n/total) & $0 / 15$ & $3 / 12$ & $<0.05$ \\
Family history & $0 / 15$ & $5 / 12$ & $<0.05$ \\
RV dysfunction & $0 / 15$ & $6 / 12$ & $<0.05$ \\
T wave inversion & $3 / 15$ & $6 / 12$ & $\mathrm{NS}$ \\
VT-LBBB morphology & $15 / 15$ & $12 / 12$ & $\mathrm{NS}$ \\
Positive biopsy & $0 / 9$ & $6 / 8$ & $<0.05$ \\
\hline
\end{tabular}

ARVD, arrhythmogenic right ventricular dysplasia; $\mathrm{BBB}$, complete bundle branch block; EF, ejection fraction; LBBB, left bundle branch block; RMVT, repetitive monomorphic ventricular tachycardia; RV, right ventricle; VT, ventricular tachycardia.

and positive late potentials on signal averaged ECG were present in seven (58\%). Endomyocardial biopsy was performed in eight patients and was diagnostic of ARVD in six (75\%).

ROUTINE ECG AND ECG DURING VENTRICULAR TACHYCARDIA

In all patients a 12 lead ECG during sinus rhythm was recorded at a paper speed of $25 \mathrm{~mm} / \mathrm{s}$ when no antiarrhythmic drug treatment was given. The heart rate was calculated from the first four complexes. Specific descriptive features of the ECG during sinus rhythm were noted ( $\mathrm{T}$ wave inversion in V2 and V3, RsR morphology in V1, presence of epsilon waves or right bundle branch block). ${ }^{6}$ The morphology of the QRS during ventricular tachycardia was analysed in leads V1 and V6.

Table 2 Characteristics of the study groups

\begin{tabular}{|c|c|c|c|}
\hline & $R M V T(n=15)$ & $A R V D(n=12)$ & $p$ value \\
\hline \multicolumn{4}{|l|}{ Routine ECG data } \\
\hline Heart rate (beats/min) & $68(15)$ & $64(17)$ & NS \\
\hline QRS-I (ms) & $78(13)$ & $89(22)$ & NS \\
\hline QRS-V1 (ms) & $90(9)$ & $103(23)$ & NS \\
\hline QRS-V6 (ms) & $86(11)$ & $94(21)$ & NS \\
\hline \multicolumn{4}{|l|}{$E C G$ data $-V T$} \\
\hline VT rate (beats/min) & $190(42)$ & $211(31)$ & NS \\
\hline Pleomorphic VT (n/total) & $1 / 15$ & $3 / 11$ & NS \\
\hline Left axis (n/total) & $2 / 15$ & $4 / 11$ & NS \\
\hline $\mathrm{ID}-\mathrm{V} 1(\mathrm{~ms})$ & $72(20)$ & $77(16)$ & NS \\
\hline ID-V6 (ms) & $77(17)$ & $67(12)$ & NS \\
\hline QS V1 (n/total) & $3 / 15$ & $9 / 11$ & $<0.05$ \\
\hline R V6 (n/total) & $15 / 15$ & $6 / 11$ & $<0.01$ \\
\hline \multicolumn{4}{|l|}{$Q T$ measurements } \\
\hline $\mathrm{QT}$ mean $(\mathrm{ms})$ & $399(29)$ & $438(68)$ & NS \\
\hline QT-V4 (ms) & $407(28)$ & $436(81)$ & NS \\
\hline QTc-V4 (ms) & $429(29)$ & $442(44)$ & NS \\
\hline QTcub-V4 (ms) & $420(18)$ & $438(52)$ & NS \\
\hline QTd (ms) & $58(24)$ & $48(18)$ & NS \\
\hline QTd' (ms) & 39 (19) & $30(14)$ & NS \\
\hline $\mathrm{aQTd}(\mathrm{ms})$ & $17(7)$ & $15(5)$ & NS \\
\hline \multicolumn{4}{|l|}{ Signal averaged ECG $(40 \mathrm{~Hz})$} \\
\hline QRS (ms) & $89(8)$ & $108(23)$ & $<0.05$ \\
\hline HFQRS (ms) & $100(15)$ & $126(25)$ & $<0.05$ \\
\hline LAS (ms) & $28(11)$ & $48(14)$ & $<0.01$ \\
\hline RMS $(\mu \mathrm{V})$ & $52(44)$ & $13(10)$ & $<0.05$ \\
\hline \multicolumn{4}{|l|}{ Morphometric analysis } \\
\hline Myocytes (\%) & $74.0(3.4)$ & $64.5(9.3)$ & $<0.05$ \\
\hline Fibrous tissue (\%) & $3.0(1.7)$ & $8.9(5.2)$ & $<0.05$ \\
\hline Fatty tissue $(\%)$ & $0.3(1.1)$ & $3.5(7.2)$ & NS \\
\hline Interstitium (\%) & $22.5(3.8)$ & $23.1(5.4)$ & NS \\
\hline
\end{tabular}

Values are means $(\mathrm{SD})$

aQTd, adjusted Qt dispersion; ARVD, arrhythmogenic right ventricular dysplasia; HFQRS, duration of filtered QRS signal; ID-V4, V6, intrinsic deflection in leads V1, V6 during ventricular tachycardia; LAS, low amplitude signal duration; QRS-I, V1, V6, QRS duration in lead I, V1, V6; QT, QT interval; QTc, QT correction with square root; QTcub, QT correction with cubic root; QTd, QT dispersion; QTd', corrected QTd; QTmean, mean QT from 12 leads; RMS, root mean square value of the last $40 \mathrm{~ms}$; RMVT, repetitive monomorphic ventricular tachycardia; VT, ventricular tachycardia.
QT AND QRS MEASUREMENTS

For QT measurements, all ECGs were enlarged to $200 \%$ and an average of three consecutive intervals was taken from all leads. ${ }^{7}$ The mean QT (QTmean) was the arithmetic mean from all 12 leads. We calculated QTc from Bazett's formula, and also by the cube root formula $\left[\mathrm{QT} /(\mathrm{RR})^{1 / 3}\right]$ from QTmean and QT in V4 (Qtcub). ${ }^{7}$ For QT dispersion, we used the difference between the maximum and the minimum QT interval (QTd), and a second, corrected parameter was calculated from the next to the longest and the next to the shortest interval (QTd'). Adjusted QT dispersion (aQTd) was calculated from QTd divided by the square root of the number of leads available for analysis. QRS duration was measured from enlarged ECGs in leads I, V1, and V6 during sinus rhythm. The intrinsic deflection (ID) of the QRS during ventricular tachycardia was measured in leads V1 and V6.

SIGNAL AVERAGED ECG

All patients were examined with the LP 2000 (Fidelity Medical, Millburn, New Jersey, USA). From X, Y, and Z leads, 200 normal beats were averaged and processed with a four pole filter between 40 and $250 \mathrm{~Hz}$. A noise level of $<1 \mu \mathrm{V}$ was required.

EJECTION FRACTION

Ejection fraction of the left ventricle was determined during normal sinus rhythm by radionuclide angiography $\left(\mathrm{Tc}^{99}\right)$.

ENDOMYOCARDIAL BIOPSY AND MORPHOMETRIC ANALYSIS

Three to five biopsy specimens were taken from the apical region of right ventricular cavity and the right ventricular septum. The biopsies were routinely processed for histology and stained with haematoxylin-eosin and by the trichrome method. Seven fields were randomly selected and studied at $\times 80$ power to avoid any overlap. Only fields in which the entire screen was occupied by tissue were analysed. Using a Kontron Mini-Mop analyser, the percentage area of the following variables was determined: myocytes, fibrous tissue, fatty tissue, and interstitium (not including the fibrous and fatty tissue in the interstitium). ${ }^{8}$ Biopsies were performed in eight patients from the ARVD group, and nine from the RMVT group.

\section{STATISTICAL ANALYSIS}

The SPSS package (4.0) was used for statistical analysis. Data are expressed as mean (SD). A non-parametric test was used to assess differences between the groups. The 0.05 level was used for significance.

\section{Results}

DEMOGRAPHIC DATA

Data for the two groups are presented in table 1. No differences were found in age and sex distribution, or in the mean values of the ejection fraction between the groups.

ROUTINE ECG

Complete right bundle branch block (RBBB) was not present in the group with RMVT, but 
Table 3 Characteristics of the study groupd after exclusion of patients with bundle branch block

\begin{tabular}{|c|c|c|c|}
\hline & $R M V T(n=15)$ & $A R V D(n=9)$ & $p$ value \\
\hline \multicolumn{4}{|l|}{ General data } \\
\hline Age (years) & $35(11)$ & $35(15)$ & NS \\
\hline $\operatorname{Sex}(M / F)$ & $15 / 0$ & $8 / 1$ & NS \\
\hline Ejection fraction (\%) & $61(8)$ & $71(14)$ & NS \\
\hline \multicolumn{4}{|l|}{ Routine ECG data } \\
\hline Heart rate (beats/min) & $68(15)$ & $65(16)$ & NS \\
\hline QRS-I (ms) & $78(13)$ & $78(8)$ & NS \\
\hline QRS-V1 (ms) & $90(9)$ & $93(14)$ & NS \\
\hline QRS-V6 (ms) & $86(11)$ & $84(14)$ & NS \\
\hline \multicolumn{4}{|l|}{ QT measurements } \\
\hline $\mathrm{QT}-\mathrm{V} 4(\mathrm{~ms})$ & $407(28)$ & $456(108)$ & NS \\
\hline QTc-V4 (ms) & $429(29)$ & $446(34)$ & NS \\
\hline QTd (ms) & $58(24)$ & $44(21)$ & NS \\
\hline QTd' (ms) & $38(19)$ & $35(12)$ & NS \\
\hline $\mathrm{aQTd}(\mathrm{ms})$ & $17(7)$ & $14(6)$ & NS \\
\hline \multicolumn{4}{|c|}{ Signal averaged ECG $(40 \mathrm{~Hz})$} \\
\hline QRS (ms) & $89(8)$ & $96(18)$ & NS \\
\hline HFQRS (ms) & $100(15)$ & $118(21)$ & NS \\
\hline LAS (ms) & $28(11)$ & $48(14)$ & $<0.01$ \\
\hline RMS $(\mu \mathrm{V})$ & $52(44)$ & $13(12)$ & $<0.05$ \\
\hline \multicolumn{4}{|l|}{ Morphometric analysis } \\
\hline Myocytes (\%) & $74.0(3.4)$ & $65.2(11.5)$ & $<0.05$ \\
\hline Fibrous tissue (\%) & $3.0(1.7)$ & $6.4(4.4)$ & NS \\
\hline Fatty tissue $(\%)$ & $0.3(1.1)$ & $3.4(8.2)$ & NS \\
\hline Interstitium (\%) & $22.5(3.8)$ & $23.2(6.1)$ & NS \\
\hline
\end{tabular}

Values are means (SD).

aQTd, adjusted Qt dispersion; ARVD, arrhythmogenic right ventricular dysplasia; HFQRS, duration of filtered QRS signal; ID-V4, V6, intrinsic deflection in leads V1, V6 during ventricular tachycardia; LAS, low amplitude signal duration; QRS-I, V1, V6, QRS duration in lead I, V1, V6 QT, QT interval; QTc, QT correction with square root; QTd, QT dispersion; QTd', corrected QTd; QTmean, mean QT from 12 leads; RMS, root mean square value of the last $40 \mathrm{~ms}$; RMVT, repetitive monomorphic ventricular tachycardia.

was present in three patients with ARVD $(\mathrm{p}<0.05)$. Most other electrocardiographic data are shown in table 2 . The differences remained non-significant when patients with bundle branch block were excluded (table 3). T wave inversion in leads V2 and/or V3 was noted in six of 12 patients in the ARVD group and in three of 15 patients in the RMVT group (NS).
ECG DURING VENTRICULAR TACHYCARDIA

Mean heart rate during ventricular tachycardia in the ARVD group was only slightly higher than in the RMVT group (table 2). More than one morphology was observed in one patient with RMVT. LBBB morphology was associated with left axis in four of 11 cases with ARVD (fig 1), but also in two of 15 cases with RMVT. All the other patients had an inferior axis associated with LBBB morphology (fig 2). In the ARVD group, the QRS complex in V1 showed a QS wave in nine patients and a rS pattern in two. In lead V6, the pattern of the QRS complex showed an $\mathrm{R}$ wave in six cases, a RS waves in two, and Rs in three. In the RMVT group, the QRS in lead V1 had a QS pattern in three patients, an $\mathrm{rS}$ pattern in seven, and an Rs pattern in one. These differences were significant ( $\mathrm{p}$ 0.05). In lead V6, the QRS morphology showed an $\mathrm{R}$ wave in all patients from this group $(p<0.01)$. No differences between groups were apparent for intrinsic deflection.

QT MEASUREMENTS

There were no significant differences between the two groups in any of the QT and QT dispersion indices (table 2), or after exclusion of bundle branch block.

SIGNAL AVERAGED ELECTROCARDIOGRAPHY

There were significant differences between the two groups for all variables (tables 2 and 3 ). In the absence of bundle branch block the differences persisted for low amplitude signal duration (LAS) and root mean square value of the last $40 \mathrm{~ms}$ (RMS). In the ARVD group, seven patients $(58 \%)$ showed late potentials, versus only three patients $(20 \%)$ in the RMVT group.
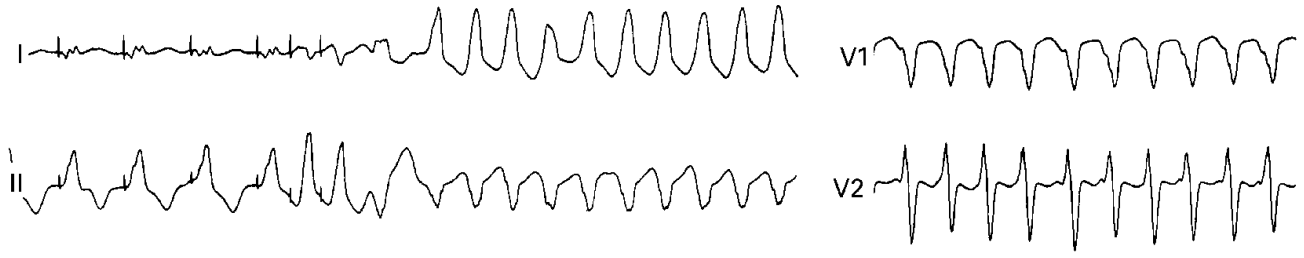
III

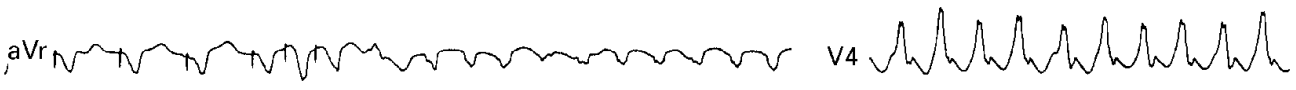

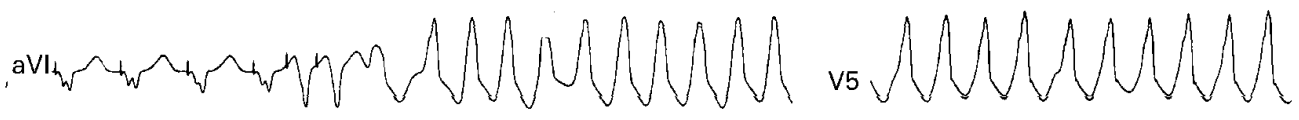

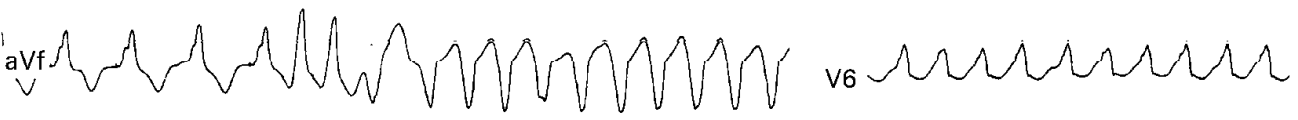

Figure 1 Programmed electrical stimulation induced sustained ventricular tachycardia with left bundle branch block and left axis. This patient with arrhythmogenic right ventricular dysplasia (ARVD) was cured from further recurrences by one radiofrequency application. 

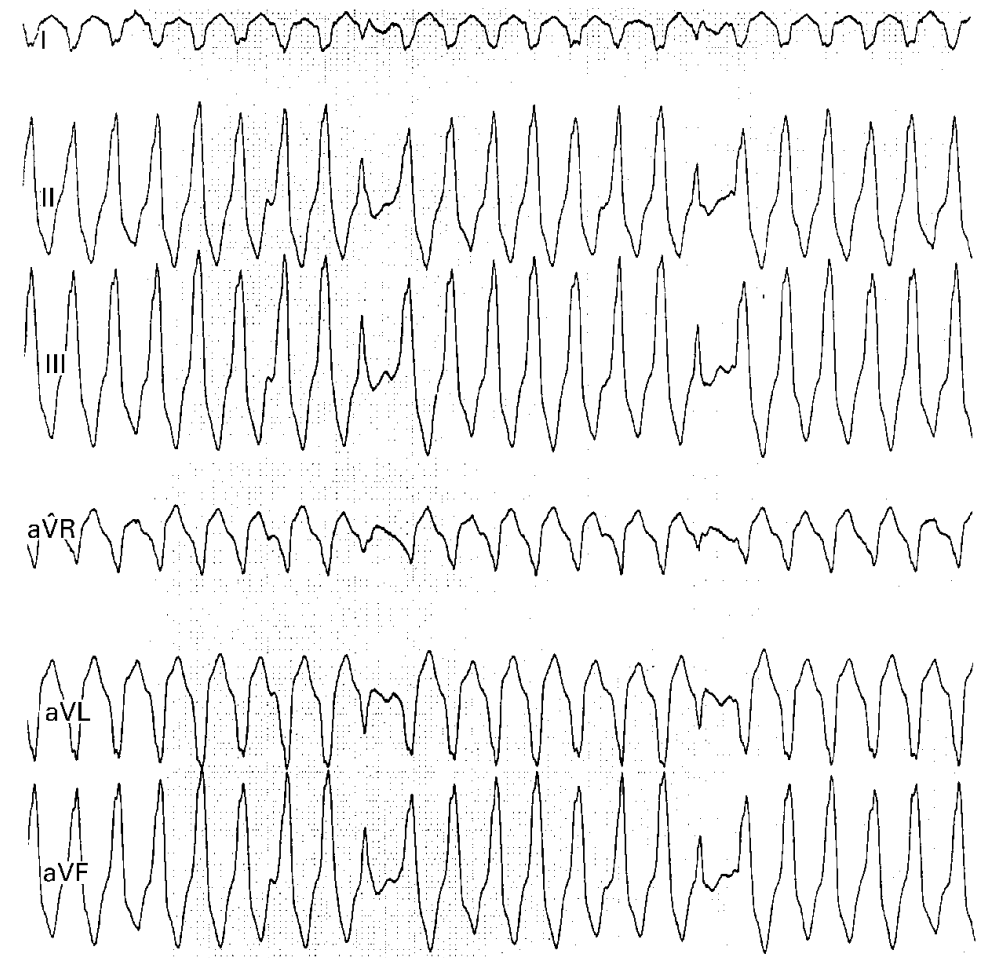

Figure 2 Tachycardia with left bundle branch block and inferior axis is interrupted by two conducted sinus beats. Familial arrhythmogenic right ventricular dysplasia.

MORPHOMETRIC DATA

As shown in tables 2 and 3, the proportion of normal myocytes in the biopsies was lower in the ARVD group than in the RMVT group $(\mathrm{p}<0.05)$. The amount of fibrous tissue was higher in the ARVD group ( $\mathrm{p}<0.05)$. No differences were found for fatty tissue and interstitium. In the absence of bundle branch block, significant differences persisted only for the myocyte area (less in the ARVD group; $\mathrm{p}<0.05)$.

CORRELATION OF PATHOLOGY WITH

ELECTROCARDIOGRAPHY

The percent of myocytes, interstitium, fibrous and fatty tissue was not correlated with clinical data, routine ECG features, QT indices, and signal averaging data within both groups, except for a positive correlation in the RMVT group between fibrosis and QTd' $(r=0.6890$; $\mathrm{p}<0.01$ ). In all patients (ARVD + RMVT), a significant correlation was detected between fibrosis and age $(r=0.6761 ; \mathrm{p}<0.01)$. QRS width was also associated with fibrosis:

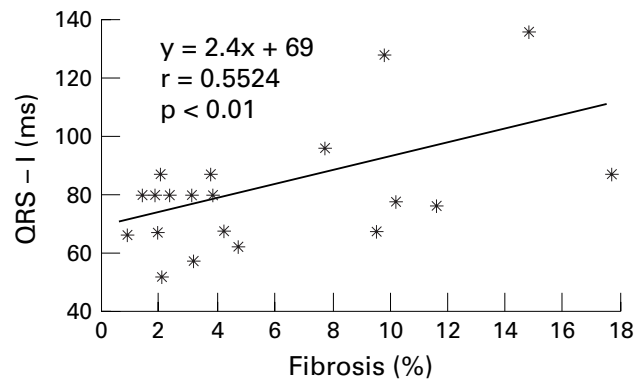

Figure 3 Relation of QRS duration in lead I and amount of fibrosis in morphometrically analysed biopsies in patients with ventricular tachycardia of right ventricular origin. $r=0.5524$ for lead I (fig 3), $r=0.5254$ for lead $\mathrm{V} 1$, and $r=0.6017$ for lead V6. All these correlations were significant $(\mathrm{p}<0.01)$.

\section{Discussion}

ARVD and RMVT are difficult clinical entities. They seem to constitute a continuous spectrum of disease, varying from a minor (RMVT) to a more severe expression (ARVD). It is therefore not surprising that new diagnostic techniques for ARVD are continuously being assessed, for example magnetic resonance imaging $^{9}$ and body surface QRST integral mapping. ${ }^{10}$ The latter was found to be abnormal in ARVD and to a lesser extend in idiopathic right ventricular tachycardia, ${ }^{10}$ in contrast to other data reporting an abnormal body surface QRST integral map in only one of six patients with ARVD. ${ }^{11}$ The discrepancy may be caused by the different severity of the disease in the two groups. These recent data prove that it is worthwhile challenging existing ideas about both diseases.

Nevertheless, some electrocardiographic criteria have been proposed for both pathologies. ${ }^{2612}$ These include criteria for the morphology of the ventricular tachycardia in RMVT, and for the resting ECG in ARVD. However, our study shows that it is almost impossible to be certain from ventricular tachycardia morphology alone whether one is dealing with RMVT, since one can have exactly the same electrocardiographic pattern during ventricular tachycardia in ARVD as in RMVT. ${ }^{13}$ The fact that LBBB morphology is the only criterion for ventricular tachycardia in ARVD puts an important restriction on the ECG criteria. Some investigators assume that an axis other than the inferior axis is a marker of organic heart disease in RMVT. ${ }^{2}$ Also, multiple ventricular tachycardia patternslogically associated with more extensive disease (and hence, more probably with ARVD) - were also present in one patient from our RMVT group, indicating that not all forms were located at a single site in the right ventricular outflow tract. ${ }^{14}$ However, one can assume that the resting ECG in ARVD is more or less specific. $^{15}$ In a group of 30 patients with ventricular tachycardia of right ventricular origin (excluding ARVD), Buxton et al found that in each patient the resting ECG was normal, and none of the characteristic abnormalities for ARVD were observed. ${ }^{16}$ Nevertheless, we were able to demonstrate $\mathrm{T}$ wave inversion in leads V1 to V3 in only $50 \%$ of ARVD patients, while it was present in $20 \%$ of the RMVT group.

A QRS duration of more than $110 \mathrm{~ms}$ in lead V1 has a sensitivity of $55 \%$ and a specificity of $100 \%$ for ARVD. ${ }^{15}$ A combination of QRS prolongation in $\mathrm{V} 1$ and $\mathrm{T}$ wave inversion in the right precordial leads improves sensitivity and specificity. ${ }^{17}$ In our study, a combination of these two features had a sensitivity of $75 \%$ and a specificity of $80 \%$, although no differences in the mean QRS duration in leads V1, V6, and I between the ARVD and the RMVT groups were observed. In the ARVD group the QRS duration was more prolonged in lead V1 than in lead V6, whereas in the 
RMVT group differences were not significant. This prolongation may reflect local delay in right ventricular activity due to morphological changes in the right ventricle (fatty and fibrofatty infiltration), as was recently described by Fontaine et al. ${ }^{17} 18$

There are no published reports about the predictive value of QT indices in ARVD. We found a QTc of $\geqslant 440 \mathrm{~ms}$ in $50 \%$ of ARVD patients, and in $20 \%$ of the RMVT group. QT dispersion in both groups was comparable to values in a healthy control. ${ }^{19}$

The presence of late potentials is one of the other minor criteria for the diagnosis of ARVD. ${ }^{6}$ The signal averaged ECG may be abnormal in $47 \%$ to $69 \%$ of patients with ARVD with clinical ventricular tachycardia. ${ }^{2021}$ In patients with ventricular tachycardia of right ventricular origin and without clinically apparent heart disease, the presence of abnormalities varies from $0 \%$ to $25 \% .{ }^{16}{ }^{22}$ We found abnormalities in $58 \%$ of ARVD patients and in $20 \%$ of patients with RMVT. In this study, only signal averaging was helpful in discriminating the ARVD and RMVT groups.

The demonstration of fibrofatty replacement of myocardium in the endomyocardial biopsy is a cornerstone of the diagnosis of ARVD. ${ }^{6}$ However, false negatives occur because of sampling errors, and it is possible that normal hearts with recurrent ventricular tachycardia show an increased amount of fibrotic tissue. ${ }^{22}$ Adipose infiltration of the myocardium, primarily the right ventricle, has also been reported in alcoholics dying suddenly, and in viral or mycoplasmal myocarditis. ${ }^{23}{ }^{24}$ Extensive adipose or fibrous infiltration occurs usually at advanced stages of ARVD. It has been suggested that amounts of fatty tissue and fibrous tissue exceeding $3.2 \%$ and $40 \%$, respectively, should be considered as highly suggestive of ARVD. ${ }^{25}$ Using morphometric techniques, we detected significantly more fibrous tissue in the ARVD group, but this value $(9 \%)$ was less than reported in other studies. ${ }^{20}{ }^{25}$ This supports the idea that we were dealing with early stages of ARVD in the majority of the ARVD group.

It has been suggested that idiopathic ventricular tachycardia is nothing other than a concealed form of ARVD. ${ }^{26}$ However, the use of magnetic resonance imaging and signal averaged electrocardiography did not support the view that RMVT is an early or localised form of ARVD. ${ }^{27}$ In contrast, Carlson et al showed that in the vast majority of patients with RVOT tachycardia there are structural abnormalities in the infundibulum area on magnetic resonance imaging. ${ }^{28}$ While ECG data are comparable in most patients with ARVD and RMVT, differences were detected during ventricular tachycardia in the signal averaged ECG and the amount of fibrous tissue and myocytes in the right ventricular endomyocardial biopsy. This lends support to the view that there are two different entities, though it is not impossible that one is a more diffuse form, or the end stage, of the other, and that in the more advanced forms more extensive abnormalities can be detected. Therefore, it would be logical for late potentials to be correlated with the extent of fibrosis in ARVD, but this was not observed in our small series. ${ }^{29}$ However, we found a consistent relation between the amount of fibrosis and the QRS width in the group as a whole. Furthermore, there are differences between younger and older patients with ARVD, lending support to the idea that this disease is a changing continuum. ${ }^{20}$

It is evident that we shall have to refine our diagnostic techniques to gain a better understanding of what is going on. Genetic markers and familial forms have been described, at least for ARVD. ${ }^{30}$ Apoptosis (programmed cell death) was proposed as a possible mechanism for the non-inflammatory loss of myocardial cells. ${ }^{31}$ If ARVD is a consequence of acquired injury (myocyte death) followed by fibrofatty replacement or patchy myocarditis, such disease could have a predilection for the right ventricular outflow tract, as the haemodynamic stress is greater there than in other parts of the right ventricle. This could explain some of the similarities between ARVD and idiopathic ventricular tachycardia arising in the outflow tract.

JK had a grant from The European Society of Cardiology for a research fellowship at The University of Ghent.

1 Fontaine G, Brestescher C, Fontaliran F, et al. Modalités évolutives de la dysplasie ventriculaire droite arythmogène. A propos de 4 observations. Arch Mal Coeur 1995;88:973A p

2 Wellens HJJ, Rodriguez LM, Smeets JL. Ventricular tachycardia in structurally normal hearts. In: Zipes DP, Jalife J, eds. Cardiac electrophysiology. From cell to bedside. Philadelphia: WB Saunders, 1995:780-8.

3 Katritisis D, Gill JS, Camm AJ. Repetitive monomorphic ventricular tachycardia. In: Zipes DP, Jalife J, eds. Cardiac electrophysiology. From cell to bedside. Philadelphia: WB Saunders, 1995:900-7.

4 Maron BJ. Right ventricular cardiomyopathy: another cause of sudden death in the young. $N \mathrm{Engl} F \mathrm{Med} 1988$;318:17880.

5 Pinamonti B, Sinagra G, Salvi A, et al. Left ventricular involvement in right ventricular dysplasia. Am Heart $\mathcal{F}$ 1992;123:711-24.

6 McKenna WJ, Thiene G, Nava A, et al. Diagnosis of arrhythmogenic right ventricular dysplasia/ arrhythmogenic right ventricular

7 Puddu PE, Jouve R, Mariotti S, et al. Evaluation of 10 QT prediction formulas in 881 middle-aged men from the Seven Countries Study: emphasis on the cubic root Friderica's equation. F Electrocardiol 1988;21:219-29.

8 Baandrup U, Olsen EGJ. Critical analysis of endomyocardial biopsies from patients suspected of having cardiomyopathy. Br Heart $\mathcal{F} 1981 ; 45: 475-86$.

9 Menghetti L, Basso C, Nava A, et al. Spin-echo nuclear magnetic resonance for tissue characterisation in arrhythmogenic right ventricular cardiomyopathy. Heart 1996;76: $467-70$

10 Peeters H, SippensGroenewegen A, Schoonderwoerd B, et al. Body-surface QRST integral mapping. Arrhythmogenic right ventricular dysplasia versus idiopathic right ventricular tachycardia. Circulation 1997;95:2668-76.

11 De Ambroggi L Nergoni MS, Santambrogio C, et al. Surface ECG mapping in patients with right ventricular dysplasia [abstract]. Eur Heart $\mathcal{F}$ 1992;13(suppl):368.

12 Coumel P, Leclercq JF, Attuel P, et al. The QRS morphology in post-myocardial infarction ventricular tachycardia. A study in 100 tracings compared with 70 cases of idiopathic ventricular tachycardia. Eur Heart $\mathcal{F}$ $1984 ; 5: 792-9$

13 Leclercq JF, Coumel P. Characteristics, prognosis and treatment of the ventricular arrhythmias of right ventricular dysplasia. Eur Heart $\mathcal{F}$ 1989;10(suppl D):61-7.

14 Trappe HJ, Brugada P, Talajic M, et al. Value of induction of pleomorphic ventricular tachycardia during programmed stimulation. Eur Heart $\mathcal{F}$ 1989;10:133-41.

15 Marcus FI, Fontaine G. Arrhythmogenic right ventricular dysplasia/cardiomyopathy: a review. PACE 1995;18:1298314 .

16 Buxton AE, Waxman HL, Marchlinski FE, et al. Right ventricular tachycardia: clinical and electrophysiologic characteristics. Circulation 1983;68:917-27.

17 Fontaine G, Tsezana R, Lazarus A, et al. Troubles de la répolarisation et de la conduction intraventriculaire dans la dysplasie ventriculaire droite arythmogène. Ann Cardiol Angeiol (Paris) 1994;43:5-10. 
18 Fontaine G, Umemura J, Di Donna P, et al. La durée des complexes QRS dans la dysplasie ventriculaire droite arythmogène. Un nouveau marquer diagnostique n

invasif. Ann Cardiol Angeiol (Paris) 1993;42:399-405.
Jordaens L, Missault L, Pelleman G, et al. Compariso

9 Jordaens L, Missault L, Pelleman G, et al. Comparison of athletes with life-threatening ventricular arrhythmias with two groups of healthy athletes and a group of normal control subjects. Am f Cardiol 1994;74:1124-8.

20 Daliento L, Turrini P, Nava A, et al. Arrhythmogenic right ventricular cardiomyopathy in young versus adult patients: similarities and differences. $\mathcal{F}$ Am Coll Cardiol 1995;25:65564 .

21 Blomström-Lundqvist C, Olsson BS, Edvardsson N. Follow-up by repeated signal-averaged surface QRS in patients with the syndrome of arrhythmogenic right ventricular dysplasia. Eur Heart f 1989;10(suppl D):54-60.

22 Mehta D, McKenna WJ, Ward D, et al. Significance of signal-averaging electrocardiography in relation to endomyocardial biopsy and ventricular stimulation studies in patients with ventricular tachycardia without clinically patients with ventricular tachycardia without clinically
apparent heart disease. $7 \mathrm{Am}$ Coll Cardiol 1989;14:372-9.

23 Strain J. Adipose dysplasia of the right ventricle: is endocardial biopsy useful? Eur Heart $\mathcal{f}$ 1989;10(suppl D):84-8.

24 Caruso G, normal component of the myocardium? Eur Heart f 1989; 10(suppl D):89-91.
25 Angelini A, Thiene G, Boffa GM, et al. Endomyocardial biopsy in right ventricular cardiomyopathy. Int $\mathcal{f}$ Cardiol biopsy in right ven

26 Nava A, Thiene G, Canciani B, et al. Clinical profile of concealed form of arrhythmogenic right ventricular cardiomyopathy presenting with apparently idiopathic ventricular arrhythmias. Int f Cardiol 1992;35:195-206.

27 Grimm W, List-Hellwig E, Hoffman J, et al. Magnetic resonance imaging and signal-averaged electrocardiography in patients with repetitive monomorphic ventricular tachycardia and otherwise normal electrocardiogram. PACE 1995; 20:1826-33.

28 Carlson M, White R, Trohman R, et al. Right ventricular outflow tract tachycardia: detection of previously unrecognized anatomic abnormalities using cine magnetic resonance imaging. $\mathcal{F}$ Am Coll Cardiol 1994;24:720-7.

29 Turrini P, Angelini A, Buja GF, et al. Fibrosis is the main cause of late potentials in arrhythmogenic right ventricula cardiomyopathy [abstract]. Circulation 1994;90:I-229.

30 Basso C, Thiene G, Corrado D, et al. Arrhythmogenic right ventricular cardiomyopathy. Dysplasia, dystrophy, or myoventricular cardiomyopathy. Dysplasia,
carditis? Circulation 1996;94:983-91.

31 Mallat Z, Tedgui A, Fontaliran F, et al. Evidence of apoptosis in arrhythmogenic right ventricular dysplasia. $N$ Engl $\mathcal{F}$ Med 1996;335:1190-6. 